\title{
ANALISA DAYA DUKUNG PONDASI BORED PILE PADA GEDUNG KANTOR SATPOL PP KOTA BUKITTINGGI
}

\author{
Nadra Arsyad ${ }^{1 *}$, Rita Nasmira Yanti ${ }^{2}$, Hidayatul Akbar ${ }^{3}$
}

1) Teknik Sipil, Fakultas Teknik Universitas Putra Indonesia "YPTK" Padang 1 (email: nadra.arsyad@gmail.com)

2) Teknik Sipil, Fakultas Teknik Universitas Putra Indonesia "YPTK" Padang 2 (email: ritanasmirayanti@upiyptk.ac.id)

3) Teknik Sipil, Fakultas Teknik, Universitas Putra Indonesia "YPTK" Padang 3 (email: akbarhidayatul31@gmail.com)

\section{$\underline{\text { Info Artikel }}$}

Riwayat Artikel:

Dikirim :04-12-21

Direvisi :06-1-22

Diterima :24-01-22

\section{Keywords :}

Pondasi Bored Pile, Data Sondir, Metode Mayerhoff

\begin{abstract}
$\underline{\text { ABSTRACT }}$
Pondasi tiang atau disebut juga pondasi dalam berfungsi untuk memikul dan menahan beban yang bekerja diatasnya yaitu beban konstruksi atas kelapisan tanah yang keras. Dalam perencanaan pondasi tiang harus dilakukan dengan teliti dan keamanan yang diterutamakan, termasuk mendukung beban maksimum yang mungkin terjadi. Tujuan dari studi ini untuk menghitung daya dukung pondasi Bored Pile dari data sondir memakai metode mayerhoff, menentukan ukuran dimensi pondasi bored pile, menentukan jumlah pondasi group yang memikul, dan metode pengumpulan data dengan metode observasi, pengambilan data dari kontraktor dan pengawas pelaksana dan melakukan studi keperpustakaan. Hasil dari perhitungan daya dukung pondasi Bored Pile sudah termasuk kategori aman dengan total sebesar 107,374 ton dan total daya dukung ijin sebesar 56,78 ton pada kedalaman 6,8 meter di satu titik, hasil analisis dimensi Bored Pile yang direncanakan berdiameter $40 \mathrm{~cm}$ dengan titik sebanyak 41 perletakan dengan pondasi 6 tipe yaitu $\mathrm{P} 1$ terdapat 19 tiang, $\mathrm{P} 2$ terdapat 10 tiang, $\mathrm{P} 3$ terdapat 8 tiang, P4 terdapat 1 tiang, P5 terdapat 2 tiang, dan P6 terdapat 1 tiang, dan berdasarkan hasil analisis perhitungan jumlah jenis pondasi pile group sebanyak 6 jenis dengan jumlah tiang yang berbeda yaitu P1 menggunakan 1 tiang, P2 menggunakan 2 tiang, P3 menggunakan 3 tiang, P4 menggunakan 4 tiang, P5 menggunakan 5 tiang, dan P6 menggunakan 1 tiang.
\end{abstract}

\section{PENDAHULUAN \\ 1.1 Latar Belakang}

Suatu bangunan tentunya tidak akan berdiri tanpa adanya pondasi. Pondasi bangunan adalah konstruksi paling penting pada pembangunan yang berfungsi sebagai penahan bangunan dan meneruskan beban bangunan di atasnya ke lapisan tanah yang memikul daya dukungnya. Pondasi berinter- aksi dengan tanah untuk menghasilkan daya dukung yang mampu memikul dan memberikan keamanan pada struktur bagian atas. Pondasi harus diperhitungkan sedemikian rupa sehingga dapat menjamin kestabilan bangunan terhadap berat sendiri, beban berguna dan gaya-gaya luar seperti angin, gempa bumi, dan lain-lain. 
Kedalaman suatu pondasi menentukan jenis pondasi apa yang akan digunakan. Berdasarkan tingkat kedalamannya pondasi terdiri dari dua jenis yaitu pondasi dangkal (shallow foundation) dan pondasi dalam (deep foundation). Pondasi dangkal digunakan pada rumah sederhana 1 hingga 2 lantai pada kedalaman (D) dan lebar pondasi (B) adalah kurang dari $1(\mathrm{D} / \mathrm{B} \leq 1)$, sedangkan pondasi dalam digunakan untuk struktur bangunan tinggi seperti perkantoran atau pencakar langit dengan kedalaman dan lebar pondasinya adalah lebih dari $4(\mathrm{D} / \mathrm{B} \geq 4)$.

Pemerintah kota Bukittinggi melakukan pembangunan Gedung tiga lantai untuk Kantor Satpol PP, oleh karena itu perlu direncanakan analisis daya dukung pondasi (Jusi, 2015; Candra et al, 2018; Fadilah et al, 2018). Rencana pondasi yang digunakan adalah pondasi Bored Pile (Saputra, 2020; Fauzih, 2019). Perencanaan pondasi bored pile dapat dilakukan dengan beberapa metode yaitu konvensional, statistik, dan probabilistik atau Load Resistance Factor Design (LRFD) (Afriyanto, 2017; Chairullah, 2013; Candra et al, 2018).

\subsection{Tujuan Penelitian}

Adapun tujuan penulisan tugas akhir ini adalah:

1. Menghitung daya dukung pondasi bored pile.

2. Menentukan ukuran dimensi pondasi bored pile.

3. Menentukan jumlah pondasi group yang memikul

\section{METODOLOGI}

Metode penelitian ini adalah untuk merencanakan langkah-langkah kerja penelitian dari pengenalan masalah, pengumpulan data, analisis data memakai metode yang sudah di tentukan sampai mendapatkan hasil dari analisis data serta kesimpulan dan saran. Langkah pertama yang dilakukan adalah mengidentifikasi permasalahan yang akan diangkat dalam penelitian ini. Selanjutnya menentukan tujuan penelitian, pengumpulan data sekunder lalu dilakukan kompilasi data dan analisis data. Dalam tahap menganalisis data, dari hasil analisis tersebut dapat diketahui hasil yang ingin dicari terangkum dalam kesimpulan

\section{a. Studi Literatur}

Penelitian yang dilakukan oleh peneliti dengan mengumpulkan sejumlah buku buku, majalah yang berkaitan dengan masalah dan tujuan penelitian. Teknik ini dilakukan dengan tujuan untuk mengungkapkan berbagai teori-teori yang relevan dengan permasalahan yang sedang dihadapi/diteliti sebagai bahan rujukan dalam pembahasan hasil penelitian.

\section{b. Pengumpulan Data}

Tahapan proses riset dimana peneliti menerapkan cara dan teknik ilmiah tertentu dalam rangka mengumpulkan data secara sistematis guna keperluan analisis, dapat diketahui bahwa bagaimana data dikumpulkan dalam penelitian tentu harus dilakukan secara ilmiah dan sistematis. Data yang dikumpulkan secara serampangan akan menghasilkan kualitas riset yang rendah, bias dan tidak valid.

c. Analisa Data dan Perhitungan

Analisis data adalah sebuah proses untuk memeriksa, membersihkan, mengubah, dan membuat pemodelan data dengan maksud untuk menemukan informasi yang bermanfaat sehingga dapat memberikan petunjuk bagi peneliti untuk mengambil keputusan terhadap pertanyaan-pertanyaan penelitian. Dalam perhitungan pondasi Bored Pile ini melakukan analisa perhitungan pondasi dengan Metoda Mayerhoff, dan perhitungan lainnya dengan menggunakan metoda yang berbeda sesuai dengan analisa perhitungan masing masing.

\section{Kapasitas Daya Dukung Tiang Bor (bored pile) Berdasarkan Data Sondir}

Menghitung daya dukung berdasarkan data SPT dengan Metode Mayerhoff (Pamungkas dan Hariyanti, 2013) adalah sebagai berikut:

Kuat dukung ultimate pondasi bored pile dinyatakan dengan rumus : 
$\mathrm{Qu}=(q c \times A p)+(J H L \times K)$

Dimana :

$\mathrm{Qu} \quad=$ Kapasitas dukung ultimate neto $(\mathrm{kg})$

qc $\quad=$ Tahanan ujung sondir $(\mathrm{kg} / \mathrm{cm} 2)$

Ap $=$ Luas penampang tiang $(\mathrm{kg} / \mathrm{m} 2)$

$\mathrm{JHL}=$ Jumlah hambatan lekat $(\mathrm{kg})$

$\mathrm{K}=$ Keliling tiang $(\mathrm{cm})$

Adapun daya dukung ijin pondasi menggunakan metode ini dinyatakan dengan rumus :

$\mathbf{Q}=\frac{(q c x A p)}{3}+\frac{(J H L x K)}{5}$

\section{Kapasitas Daya Dukung Ijin Untuk \\ Kelompok Tiang}

Daya dukung sebuah tiang dalam kelompok adalah sama dengan daya dukung tiang tersebut dikalikan factor efisiensi (Hardiyatmo, 2015) :

$$
\boldsymbol{Q p g}=\boldsymbol{E} \boldsymbol{g} \times \boldsymbol{n} \times \boldsymbol{Q u}
$$

Dimana:

Qpg = daya dukung yang di izinkan

kelompok tiang $(\mathrm{kg} / \mathrm{cm})$

$\mathrm{Eg} \quad=$ Efesiensi kelompok tiang $(\mathrm{kg} / \mathrm{cm} 2)$

$\mathrm{n} \quad=$ Jumlah tiang

$\mathrm{Qu} \quad=$ Daya dukung ultimate untuk tiang tunggal $(\mathrm{kg})$

Menghitung efisensi dari sebuah kelompok tiang (Eg), rumus yang digunakan untuk menghitung efisiensi dari sebuah kelompok tiang adalah tiang diambil dari rumus Converse Labarre (Bowles, 1992), yaitu :

$\mathbf{E g}=1-\Theta \frac{(n-1) m+(m-1) n}{90 m n}$

Dimana:

Eg = Efisiensi kelompok tiang $\left(\mathrm{m}^{2}\right)$

$\Theta \quad=\arctan (\mathrm{D} / \mathrm{S})$ dalam derajat $\left({ }^{\circ}\right)$

$\mathrm{n} \quad=$ Jumlah tiang dalam satu baris $\left(\mathrm{m}^{2}\right)$

$\mathrm{m} \quad=$ Jumlah tiang dalam satu kolom $\left(\mathrm{m}^{2}\right)$

\section{Jumlah Tiang Yang Diperlukan}

Perhitungan jumlah tiang yang diperlukan pada suatu titik kolom menggunakan beban aksial dengan kombinasi bebal DL + LL (beban tak terfaktor). Jumlah tiang yang diperlukan dihitung dengan membagi gaya aksial yang terjadi dengan gaya dukung (Zain et al, 2021).

$n p=\frac{P}{Q a}$.

dimana :

$\mathrm{np} \quad=$ Jumlah tiang

$\mathrm{P} \quad=$ Gaya aksial yang terjadi

Qa $\quad=$ Daya dukung ijin tiang

\section{d. Kesimpulan}

Kesimpulan merupakan sebuah bentuk dari sebuah proposisi (sebuah kalimat yang disampaikan) yang dimana kemudian diambil dari sebuah bentuk beberapa premis (atau ide pemikiran) dengan berbagai macam bentuk aturan dari inferensi (atau yang di mana berlaku). Sebuah kesimpulan merupakan sebuah bentuk gagasan yang dimana kemudian akan tercapai pada sebuah akhir pembicaraan.

\section{HASIL DAN PEMBAHASAN}

3.1 Menghitung kapasitas daya dukung pondasi Bored Pile dari data sondir

Perhitungan dititik Pl30 (S-2) pada kedalaman bored pile 6,8 meter.

$$
\begin{aligned}
\mathrm{qc} & =\frac{\text { jumlah perlawanan konus }}{n} \\
& =\frac{2551}{35}=75,029 \mathrm{~kg} / \mathrm{cm} 2 \\
\mathrm{Ap} & =0,25 \times \pi \times 40^{2} \\
\mathrm{~K} & =1256 \mathrm{~cm} 2 \\
& =\pi \times 40 \mathrm{~cm} \\
& =125,6 \mathrm{~cm}
\end{aligned}
$$

Perhitungan kapasitas daya dukung ultimate tiang pada titik pada Mayerhoff adalah sebagai berikut:

$$
\begin{array}{ll}
\mathrm{qc} & =75,029 \mathrm{~kg} / \mathrm{cm} 2 \\
\mathrm{Ap} & =1256 \mathrm{~cm} 2 \\
\mathrm{JHL} & =123,92 \mathrm{~kg} / \mathrm{cm} \\
\mathrm{K} & =125,6 \mathrm{~cm}
\end{array}
$$


Maka Qu $=(\mathrm{qc} \times \mathrm{Ap})+(\mathrm{JHL} \times \mathrm{K})$

$$
\begin{aligned}
& =(75,029 \times 1256)+(123,92 \times 125,6) \\
& =107374 \mathrm{~kg}=107,374 \mathrm{ton}
\end{aligned}
$$

Faktor aman :

$$
\begin{aligned}
\mathrm{Q} a & =\frac{(75,029 \times 1256)}{3}+\frac{(123,92 \times 125,6)}{5} \\
& =31468,217 \mathrm{~kg}=31,468 \mathrm{ton}
\end{aligned}
$$

Jumlah tiang yang diperlukan :

$$
\begin{aligned}
\eta & =\frac{P}{\text { Qall }} \\
& =\frac{130,36}{31,468}=4,143 \approx 5 \text { buah tiang }
\end{aligned}
$$

Jarak antar bored pile untuk $\mathrm{S}>2,5-3 \mathrm{D}$

Jarak minimum antar bored pile

$=2,5 \mathrm{D}=2,5 \times 0,4=1 \mathrm{~m}$

Jarak maksimum antar bored pile

$=3 \mathrm{D}=3 \times 0,4=1,2 \mathrm{~m}$

Diambil :

- Jarak bored pile $=1 \mathrm{~m}$

- Jarak bored pile ke tepi $=0,4 \mathrm{~m}$

Efesiensi kelompok tiang titik Pl-30

\subsection{Menghitung kapasitas daya dukung pondasi Bored Pile dari data sondir}

Perhitungan dititik Pl30 (S-2) pada kedalaman bored pile 6,8 meter

Nilai qc diambil rata-rata seperti tabel diatas

$$
\begin{aligned}
\mathrm{qc} & =\frac{\text { jumlah perlawanan konus }}{n} \\
& =\frac{2551}{35}=75,029 \mathrm{~kg} / \mathrm{cm} 2 \\
\mathrm{Ap} & =0,25 \times \pi \times 40^{2}=1256 \mathrm{~cm} 2 \\
\mathrm{~K} & =\pi \times 40 \mathrm{~cm}=125,6 \mathrm{~cm}
\end{aligned}
$$

Perhitungan kapasitas daya dukung ultimate tiang pada titik pada Mayerhoff dalam Zain et al (2021) adalah sebagai berikut:

$$
\begin{array}{ll}
\mathrm{qc} & =75,029 \mathrm{~kg} / \mathrm{cm} 2 \\
\mathrm{Ap} & =1256 \mathrm{~cm} 2 \\
\mathrm{JHL} & =123,92 \mathrm{~kg} / \mathrm{cm}
\end{array}
$$

$$
\begin{aligned}
& \mathrm{K} \quad=125,6 \mathrm{~cm} \\
& \text { Maka Qu }=(\mathrm{qc} \times \mathrm{Ap})+(\mathrm{JHL} \times \mathrm{K}) \\
& =(75,029 \times 1256)+(123,92 \times 125,6) \\
& =107374 \mathrm{~kg}=107,374 \text { ton }
\end{aligned}
$$

Faktor aman :

$$
\begin{aligned}
\mathrm{Qa} & =\frac{(75,029 \times 1256)}{3}+\frac{(123,92 \times 125,6)}{5} \\
& =31468,217 \mathrm{~kg}=31,468 \mathrm{ton}
\end{aligned}
$$

Jumlah tiang yang diperlukan :

$\eta=\frac{\mathrm{P}}{\text { Qall }}=\frac{130,36}{31,468}=4,143 \approx 5$ buah tiang

Jarak antar bored pile untuk $\mathrm{S}>2,5-3 \mathrm{D}$ Jarak minimum $=2,5 \cdot \mathrm{D}=2,5 \times 0,4=1 \mathrm{~m}$ Jarak maksimum $=3 \cdot \mathrm{D}=3 \times 0,4=1,2 \mathrm{~m}$ Diambil:

- Jarak bored pile $=1 \mathrm{~m}$

- Jarak bored pile ke tepi $=0,4 \mathrm{~m}$

Efesiensi kelompok tiang titik Pl-30

$=0,718 \times 6 \times 31,468$

$=135,564$ ton $>\mathrm{Pu}=130,36$ ton $(\mathrm{OK})$

(pada titik Pl-30)

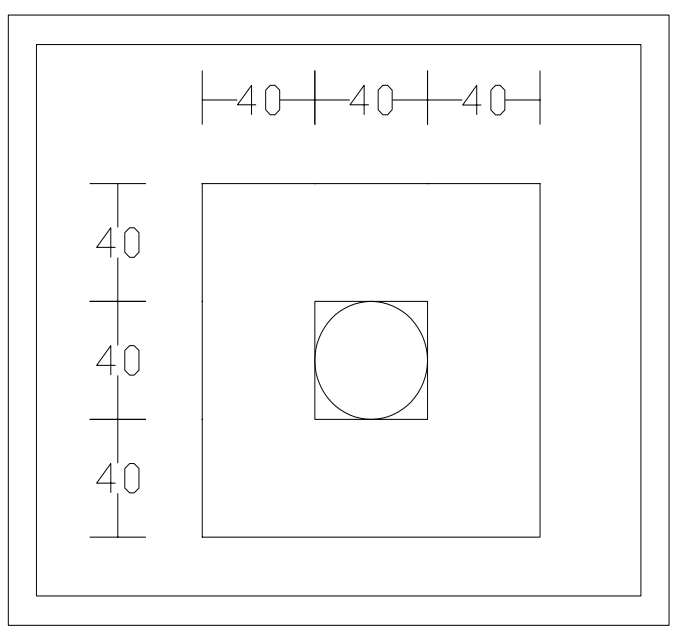

Gambar 1. Pondasi P1 


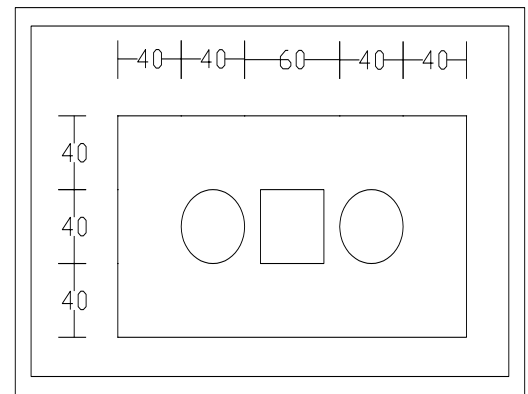

Gambar 2. Pondasi P2

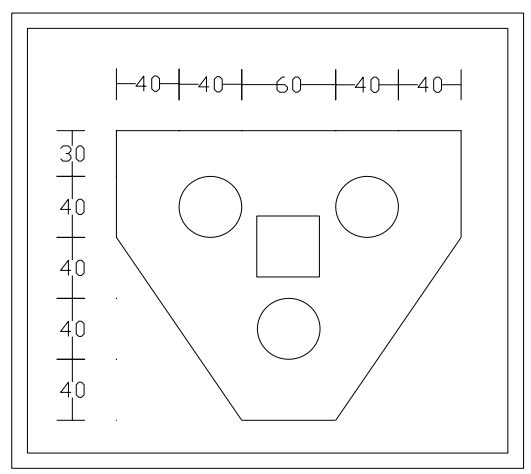

Gambar 3. Pondasi P3

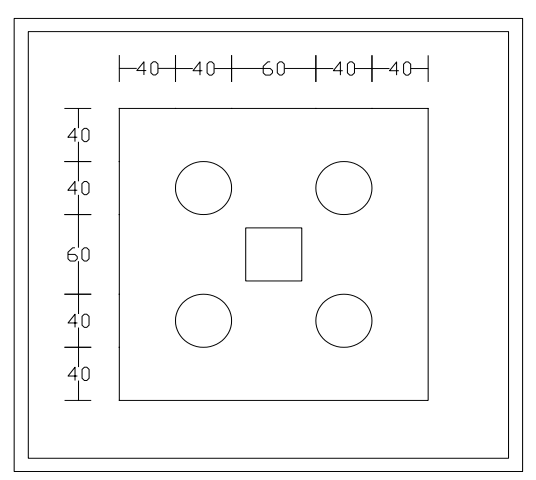

Gambar 4. Pondasi P4

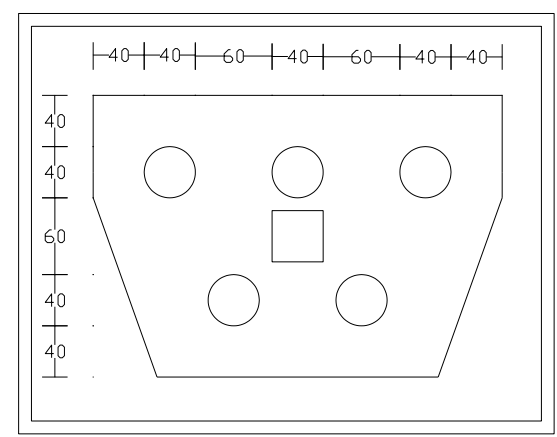

Gambar 5. Pondasi P5

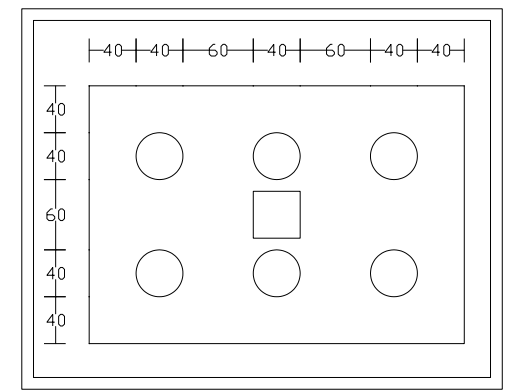

Gambar 6. Pondasi P6

Keterangan :

- $\quad \mathrm{P} 1=$ pondasi 1 tiang

- $\quad \mathrm{P} 2=$ pondasi 2 tiang

- $\quad \mathrm{P} 3=$ pondasi 3 tiang

- $\quad \mathrm{P} 4=$ pondasi 4 tiang

- $\quad$ P5 = pondasi 5 tiang

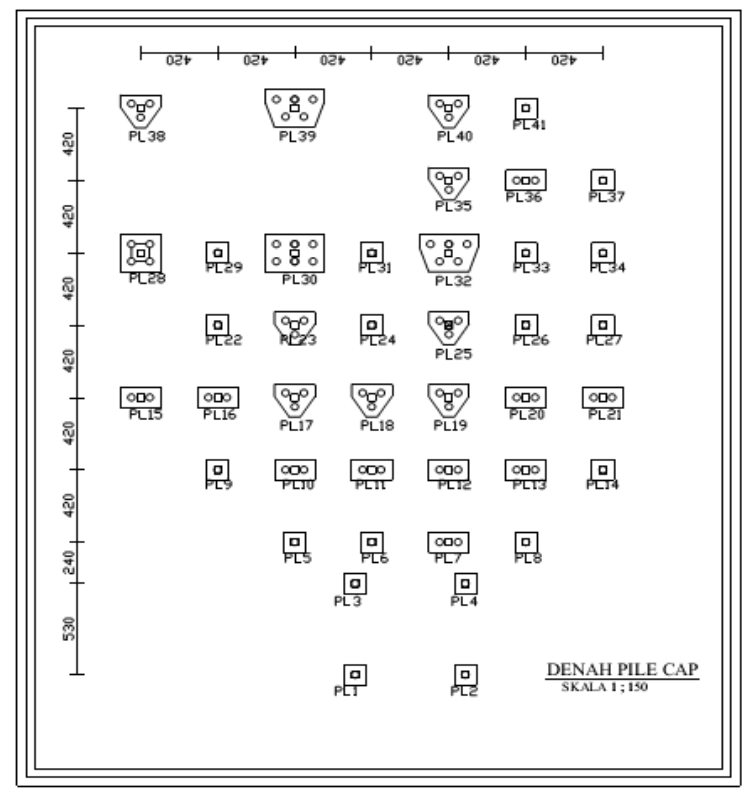

Gambar 7. Denah Pile Cap 


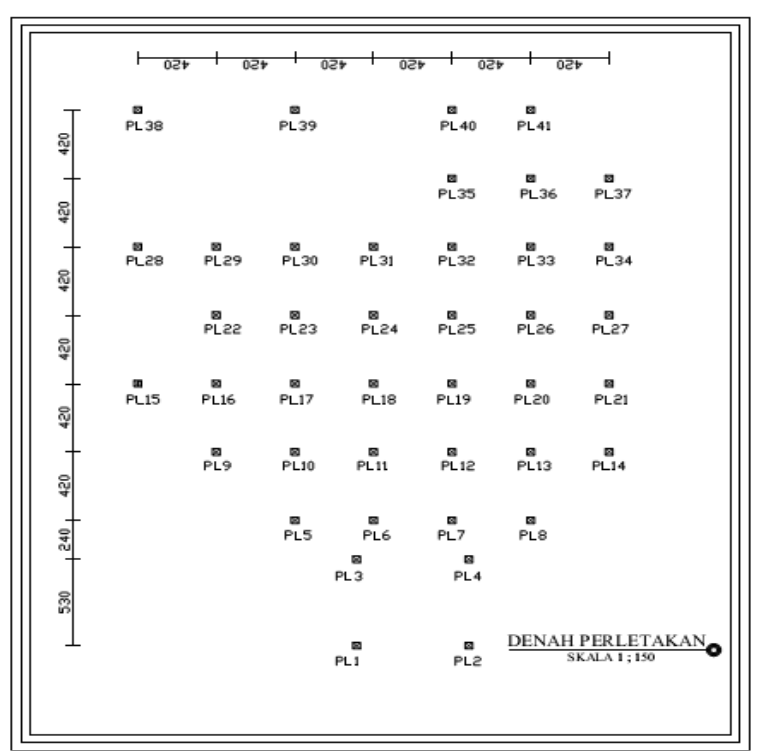

Gambar 8. Denah Perletakan

\subsection{Kapasitas Daya Dukung Kelompok Tiang}

Untuk mendapatkan kapasitas daya dukung kelompok pada titik Pl 30 adalah 31,468 ton sehingga jumlah tiang yang diperlukan adalah 5 buah tiang, karena daya dukung kelompok tiang kurang efisien ditambah satu tiang agar gaya daya dukung vertikal kelompok tiang menjadi lebih efisien menjadi 6 buah tiang.

\section{KESIMPULAN}

1. Perhitungan analisa daya dukung pondasi bored pile pada kedalaman 6,8 meter pada satu titik Pl30 (S2) dengan menggunakan metode Mayerhoff didapatkan dengan hasil sebesar 107,374 ton, dan daya dukung izin sebesar 31,462 Ton.

2. Berdasar hasil analisis dimensi bored Pile yang direncanakan berdiameter $40 \mathrm{~cm}$ dengan titik sebanyak 41 perletakan dengan pondasi 6 tipe.yaitu P1terdapat 19 tiang, P2 terdapat 10 tiang, $\mathrm{P} 3$ terdapat 8 tiang, $\mathrm{P} 4$ terdapat 1 tiang, P5 terdapat 2 tiang, dan P6 terdapat 1 tiang.

3. Berdasarkan hasil analisis perhitungan jumlah jenis pondasi pile group sebanyak 6 jenis dengan jumlah tiang yang berbeda yaitu P1 menggunakan 1 tiang, P2 menggunakan 2 tiang, P3 menggunakan 3 tiang, P4 menggunakan 4 tiang, P5 menggunakan 5 tiang, dan P6 menggunakan 1 tiang.

\section{UCAPAN TERIMA KASIH}

Terima kasih kepada pihak-pihak yang telah membantu dalam penyelesaian penelitian ini dan terkhusus untuk Kantor Satpol PP Bukittinggi yang telah mendukung penelitian ini baik secara moril ataupun materiil hingga penelitian ini dapat terselesaikan sesuai dengan yang diharapkan.

\section{DAFTAR PUSTAKA}

Afriyanto, A. (2017). Analisa Perbandingan Perencanaan Pondasi Tiang Pancang Menggunakan Berbagai Macam Metode Pada Proyek Apartemen The Frontage Surabaya. Tugas Akhir. Jurusan Teknik Sipil Fakultas Teknik Sipil dan Perencanaan Institut Teknologi Sepuluh Nopember.

Anugrah, P. \& Hariyanti, E. (2013) Desain Pondasi Tahan Gempa. Penerbit Andi. Yogyakarta.

Bowles, J. E. (1992). Analisa dan Desain Pondasi Jilid 2, Edisi Keempat, Erlangga. Jakarta.

Chairullah, B. (2013). Analisa Daya Dukung Pondasi Dengan Metoda SPT, CPT, dan Meyerhof Pada Lokasi Rencana Konstruksi Pltu Nagan Raya Provinsi Aceh. Teras Jurnal Jurusan Teknik Sipil Fakultas Teknik Universitas Malikussaleh, 3(1), pp. 15-24.

Candra, A. I., Yusuf, A., \& F, A. R. (2018). Studi Analisis Daya Dukung Pondasi Tiang Pada Pembangunan Gedung LP3M Universitas Kadiri. Jurnal CIVILa, 3(2), pp. 166-171.

Chandra, A., Yanti, G., \& Megasari, S. W. (2018). Analisis Daya Dukung Pondasi Bored Pile pada Proyek Pembangunan Menara Listrik Transmisi 500 KV Peranap-Perawang. Jurnal Teknik. 12(2), pp. 171-178.

Fadilah, U. N., \& Tunafiah, H. (2018). Analisa Daya Dukung Pondasi Bored Pile Berdasarkan Data N-SPT Menurut Rumus Reese \& Wright Dan Penurunan. IKRAITH Teknologi: Jurnal Sains \& Teknologi, 2(3), pp. 1-7. 
Hardiyatmo H.C. (2015). Analisis dan Perancangan Pondasi II. Edisi Ketiga. Yogyakarta: Gadjah Mada University Press.

Jusi, U. (2015). Analisa Kuat Dukung Pondasi Bored Pile Berdasarkan Data Pengujian Lapangan (Cone and N-Standard Penetration Test). 1(2), 50-82.

Mayerhof, G. G. (1956). Penetration tests and bearing capacity of cohesionless soils. ASCEJ Soil Mech Found Div 82:8661019.

Saputra, Z. (2020). Analisis daya Dukung Pondasi Bored Pile Tunggal Diameter 0,6 $m$ pada Proyek Perencanaan Gedung Rawat Inap \& Diagnostik Center RS. Bhayangkara Tebing Tinggi. Tugas Akhir Departemen Teknik Sipil Universitas Sumatera Utara Medan.
SNI 03. 1989. Perencanaan Pembebanan Untuk Rumah dan Gedung.

Fauzih, R. A., Najib, N., \& Santi, N. (2019). Analisis Daya Dukung Bored Pile Pada Pembangunan Pondasi Jembatan Kali Kenteng dan Kali Serang Segmen Susukan di Ruas Jalan Tol Salatiga-Kartasura, PT. Waskita Karya (Persero), Kabupaten Semarang, Provinsi Jawa Tengah. Jurnal Geosains dan Teknologi, 2(2), 87-97. https://doi.org/10.14710/jgt.2.2.2019.87-97 Wibarini, N. D., \& Zakiah, S. (2016). Perencanaan Pondasi Bored Pile Pada Gedung Parkir Politeknik Negeri Bandung. Tugas Akhir. Jurusan Teknik Sipil Politeknik Negeri Bandung. 